\title{
Hope and Optimism as Predictors of Academic Performance and Subjective Well- Being in College Students
}

\author{
Kevin L. Rand, Mackenzie L. Shanahan, Ian C. Fischer, and Sarah K. Fortney \\ Indiana University-Purdue University at Indianapolis \\ Department of Psychology \\ Corresponding author: Kevin L. Rand \\ Email: klrand@iupui.edu \\ Phone: 317-274-6771, \\ Fax: 317-274-6756 \\ Postal Address: 402 North Blackford Street \\ Indianapolis, IN 46202-3275 \\ Declaration of Interest: none.
}

\begin{abstract}
Objective: Snyder's (1994) hope and Scheier and Carver's (1985) optimism have been shown to independently predict academic performance and changes in subjective wellbeing. This study seeks to clarify their unique associations.

Method: An undergraduate class $(\mathrm{N}=334,59.6 \%$ female, $75.7 \%$ Caucasian, $\mathrm{M}=19.89$ years) was studied at two time points in a semester. Students predicted their expected grade in the course and completed measures of hope, optimism, and subjective well-being (i.e., positive affect, negative affect, and life satisfaction) the first week of classes. The final week of classes, students completed subjective well-being measures and final grades were obtained from the instructor.

Results: Path analysis showed that hope, but not optimism, predicted grade expectancy. Grade expectancy, in turn, predicted final grades, even after controlling for previous academic achievement. Hope did not directly predict final course grade, but had a
\end{abstract}

This is the author's manuscript of the article published in final edited form as:

Rand, K. L., Shanahan, M. L., Fischer, I. C., \& Fortney, S. K. (2020). Hope and optimism as predictors of academic performance and subjective well-being in college students. Learning and Individual Differences, 81, 101906. https://doi.org/10.1016/j.lindif.2020.101906 
significant indirect effect through grade expectancy. Path analysis showed that hope significantly predicted increases in positive affect and life satisfaction over the semester; whereas, optimism predicted decreases in negative affect.

Conclusion: These findings extend previous research demonstrating that hope and optimism, while conceptually similar, have differential longitudinal associations with academic performance and subjective well-being among college students.

Keywords: hope, optimism, academic performance, subjective well-being 


\section{Introduction}

College education is a critical phase that helps individuals launch successful careers and lead productive lives. Students who experience better academic achievement in college have more successful careers (Kool, Mainhard, Jaarsma, Brekelmans, \& van Beukelen, 2016) and experience better life outcomes (Kuncel, Ones, \& Sackett, 2010). Academic achievement is the primary focus of college education. However, student wellbeing is increasingly of interest for educators and researchers (Seligman, Ernst, Gillham, Reivich, \& Linkins, 2009). Student psychological well-being has been linked to better academic performance (Frisch et al., 2005) and future professional success (Samuel, Bergman, \& Hupka-Brunner, 2013). Moreover, society benefits from having citizens high in psychological well-being because they are healthier and more productive (Cummins, Lau, Mellor, \& Stokes, 2009; Lyubomirsky et al., 2005). Education has a significant impact on academic achievement and psychological well-being. Hence, we have a vested interest in creating a college experience that not only fosters academic performance but also optimizes psychological well-being (Seligman et al., 2009). Hence, we need to understand factors that predict academic performance and psychological well-being among college students.

Expectancies, beliefs about the future, are powerful predictors of academic performance and psychological well-being (Bandura, 1977). For example, academic expectancies predict cumulative grade point average during the first year of college (Friedman \& Mandel, 2009). Also, efficacy expectancies predict greater reduction in symptoms among patients treated for anxiety (Keefe, Amsterdam, Li, Soeller, DeRubeis, \& Mao, 2017). Bandura (1977) focused on the importance of specific expectancies, but 
generalized expectancies are also important predictors of performance and well-being (Magaletta \& Oliver, 1999; Snyder et al., 2002). Two of the most widely-studied generalized expectancies are hope (Snyder, 1994, 2002) and optimism (Scheier \& Carver, 1985). Both constructs involve the general belief that desired future outcomes (i.e., goals) are likely. This belief purportedly influences coping behaviors and goal achievement (Snyder et al., 1991; Snyder et al., 2002). The extent to which goals are achieved, in turn, influences psychological well-being (Brunstein, 1993).

Research suggests hope and optimism are important predictors of academic performance and psychological well-being. For example, hope predicts better academic performance, even when controlling for intelligence and previous academic achievement (Feldman \& Kubota, 2015; Author, Year a; Author, Year b; Snyder et al., 2002). Higher hope also predicts better psychological well-being (Irving, Crenshaw, Snyder, Francis, \& Gentry, 1990; Kwon, 2002). Similarly, optimism predicts better performance in academics (Chemers, Hu \& Garcia, 2001) and improved psychological well-being (Carver, Pozo, et al., 1993; Cozzarelli, 1993; Scheier et al., 1989).

Because of the similarities between hope and optimism, there is a need to clarify the distinctions between these two constructs (Aspinwall \& Leaf, 2002). To date, research has shown that hope and optimism are moderately correlated, but structurally distinct (Bryant \& Cvengros, 2004; Gallagher \& Lopez, 2009; Magaletta \& Oliver, 1999). A potential distinction is the source of hopeful versus optimistic beliefs. Hopeful expectancies are anchored in the perception that an individual's personal efforts will lead to positive futures (i.e., pathways and agentic thinking; Snyder et al., 1991). Alternately, optimistic expectancies are more general, and positive futures are thought to be derived 
from several sources (i.e., perceptions about others, luck, etc.; Scheier \& Carver, 1985). This difference may explain when hope and optimism are most influential.

When examined together, hope, but not optimism, has been found to predict academic performance (Author, Year b). However, both have been shown to be important predictors of psychological well-being, even when studied together. For example, Magaletta and Oliver (1999) found that both hope and optimism predicted general wellbeing among college students. Similarly, Author (Year b) found that hope and optimism measured at the start of the semester independently predicted life satisfaction near the end of the semester among first-year law students. Hope and optimism have also been shown to uniquely predict overall life satisfaction among university students and communitydwelling adults (Bailey, Eng, Frisch, \& Snyder, 2007).

Emerging research suggests that psychological well-being is a complex construct. For example, one operationalization of psychological well-being, subjective well-being (Diener, 1984), comprises both emotional and cognitive aspects. Hope and optimism may differentially relate to various aspects of psychological well-being. For example, Gallagher and Lopez (2009) examined the unique contributions of hope and optimism in predicting facets of psychological well-being. They found that optimism was a stronger predictor of hedonic well-being (i.e., greater pleasure and less pain) than hope. Conversely, hope was more strongly associated with eudaimonic well-being (i.e., satisfaction derived from a sense of meaning; see Ryan \& Deci, 2001) than optimism.

\section{The Present Study}


Our goal for the present study was to replicate and extend research on hope and optimism in undergraduates in predicting two important outcomes: 1) academic performance and 2) subjective well-being. Regarding academic performance, only one study to date (Author, Year a) has examined the unique roles of hope and optimism as predictors of undergraduate academic performance. A separate study examined the relative roles of hope and optimism in predicting academic performance among first-year law students (Author, Year b). However, these results may not generalize to undergraduate populations. Given the well-documented replication crisis in much of psychology (Lilienfeld, 2017), we wanted to test whether those results would replicate in a completely separate sample of undergraduate students. We also extended the previous study among undergraduates (Author, Year b) by including, when available, college grade point average (GPA) as an indicator of previous academic achievement rather than relying solely on high school GPA. We believed this was a more valid indicator of previous college academic achievement. In addition, this allowed us to directly compare high school versus college GPA as predictors of academic expectancy and performance.

The only extant study examining the relative roles of hope and optimism in predicting subjective well-being among students involved first-year law students (Author, year b). Hence, it remains unclear if those results generalize to undergraduate students. In addition, that study only predicted a single facet of subjective well-being (i.e., life satisfaction) at one time point near the end of the semester. Subjective well-being is conceptualized as comprising multiple facets (e.g., emotional and cognitive dimensions; Diener, 1984) that can change independently over time. Moreover, both theory and research suggest that hope and optimism may relate differentially to the different facets 
of psychological well-being (Gallagher \& Lopez. 2009). Therefore, we wanted to expand existing research by examining the unique roles of hope and optimism in predicting changes in different facets of subjective well-being over the course of the semester.

We had two aims for the present study. First, we wanted to replicate and extend research showing that hope and optimism differentially predict academic performance of college students, using a sample of undergraduate students, independent from our prior research. We predicted that higher hope, but not optimism, would predict better academic performance in an undergraduate class. We made this prediction based on hope, in contrast to optimism, being specifically anchored in perceptions of one's personal abilities and the fact that academic performance is largely a controllable outcome. In addition, we predicted that hope's association with academic performance would be mediated through specific grade expectancy. Second, we wanted to extend previous research showing that hope and optimism predict changes in student subjective wellbeing over the course of a semester. We predicted that both hope and optimism would predict improvements in student subjective well-being. Specifically, we predicted that hope, but not optimism, would predict changes in the eudaimonic aspect of subjective well-being (i.e., life satisfaction). Conversely, we predicted that optimism, but not hope, would predict changes in the hedonic aspects of subjective well-being (i.e., positive and negative affect). 
Method

\section{Sample Characteristics}

The total of 334 undergraduate students (199 women, 131 men, and 4 who did not indicate gender) in a large psychology class at a Midwestern university participated in the study as part of a dissertation. Students received extra credit in their psychology course in exchange for participating in the study. The mean age was 19.89 years $(S D=2.28)$, and the majority of students $(53.9 \%)$ were freshmen. The sample was primarily Caucasian (75.7\%), with smaller groups of African American (6.0\%), Hispanic (3.9\%), Asian American (1.8\%), and Native American (0.3\%) participants. Several participants identified race as "other" $(4.5 \%)$ or did not indicate race $(7.8 \%)$. A total of 233 participants completed Time 2 measures.

\section{Measures}

Optimism. The Life Orientation Test-Revised (LOT-R; Scheier et al., 1994) is a 10-item measure of trait optimism (e.g., "In uncertain times, I usually expect the best"). The scale comprises six scored items and four distractor items. Participants used a fivepoint Likert-type scale ranging from 0 (strongly disagree) to 4 (strongly agree) to rate their agreement with each item. The LOT-R was found to correlate .95 with the original LOT scale (Scheier \& Carver, 1985; Scheier et al., 1994). Higher scores on the LOT-R indicate greater levels of optimism. Research in undergraduate populations has shown the LOT-R to have good internal consistency (Cronbach's alpha = .78; Scheier et al., 1994) and temporal reliability (4-month test-retest reliability $r=.68$; Scheier et al., 1994).

Hope. The Adult Hope Scale (AHS; Snyder, Harris, et al., 1991) is a 12-item measure of trait hope. Four items measure agency (e.g., "I energetically pursue my 
goals"); four items measure pathways (e.g., "I can think of many ways to get out of a jam"); and four distractor items that are not scored. Participants used an 8-point Likerttype scale ranging from 1 (definitely false) to 8 (definitely true) to rate their agreement with each item. Higher scores on the AHS indicate greater levels of hope. Research in undergraduate populations has shown the AHS to have good internal consistency (Cronbach's alpha $=.74-.84$; Snyder, Harris, et al., 1991) and temporal reliability (10week test-retest reliability $r=.76-.82$; Snyder, Harris, et al., 1991).

Positive and Negative Affect. The Positive and Negative Affect Scale (PANAS; Watson, Clark, \& Tellegen, 1988) is a 20 -item measure of affect. Ten items assess positive affect (e.g., "interested), and ten items assess negative affect (e.g., "distressed"). Participants used a five-item Likert-type scale ranging from 1 (very slightly or not at all) to 5 (extremely) to rate their current mood. Higher scores on each sub-scale indicate greater positive or negative affect. Research in undergraduate populations has shown the PANAS to have good internal consistency (Cronbach's alphas $=.86$ to .90 for positive affect and .84 to .87 for negative affect; Watson, Clark, \& Tellegen, 1988).

Life Satisfaction. The Satisfaction with Life Scale (SWLS; Diener et al., 1985) is a five-item self-report measure of life satisfaction (e.g., "In most ways my life is close to ideal"). Respondents are asked to rate the extent to which they agree with each item on a seven-point Likert-type scale ranging from 1 (strongly disagree) to 7 (strongly agree). Higher scores on the SWLS indicate greater life satisfaction. Previous research has shown the SWLS to be internally consistent (Cronbach's alpha of .87; Diener et al., 1985) for undergraduate populations. 
Grade Expectancy. Students' predicted their class grade as a representation of specific expectancy for their academic performance. Participants were asked to complete the following sentence: "I predict that my actual final grade will be $\%$ (e.g., $70 \%, 80 \%$, etc.) in this class."

Academic Performance. Final course grade (i.e., percentage of total points) was used to indicate academic performance. The final course grade was provided at the end of the semester by the course instructor.

Previous Academic Achievement. Approximate high school or college grade point average was used to indicate previous academic achievement. For first-semester freshman $(n=180)$, high school grade point average was used. In contrast, college grade point average was used for all other participants $(\mathrm{n}=154)$.

Procedure

All study procedures followed ethical guidelines regarding human subjects research, including consent and voluntary participation. Study procedures were approved by the university's Institutional Review Board. Students completed a general informed consent as well as consent to have their course grades obtained from their instructor. In the first week of the semester (Time 1), students completed a questionnaire including demographic information, self-reported high school or college grade point average, and self-report measures of hope, optimism, positive affect, negative affect, and life satisfaction. At this time, students predicted what grade in terms of percentage of total points (e.g., $85 \%$ ) they would receive in the psychology course. During the last week of classes (Time 2), students again completed self-report measures of positive affect, 
negative affect, and life satisfaction. After the semester was over, the instructor provided students' final course grades.

Analyses

Path analyses were conducted with maximum likelihood estimation using MPlus 8.2 (Muthén \& Muthén, 2018). Two path models were created, corresponding to the two study aims examining: 1) student academic performance; and 2) changes in subjective well-being over the semester.

For the first aim, we used a mixed latent-variable/measured-variable path model that included hope, optimism, and previous academic achievement (i.e., high school or college GPA) modeled as exogenous predictors, grade expectancy modeled as the mediator, and final course grade modeled as the outcome variable. Hope and optimism were modeled as latent variables, with three parceled indicators of optimism and four parceled indicators of hope (Little, Cunningham, Shahar, \& Widaman, 2002).

For the second aim, we used a simple panel, measured-variable model to predict changes in subjective well-being over the course of the semester. We included positive affect, negative affect, and life satisfaction measured at Time 2, all auto-regressed onto their corresponding Time 1 measures, as outcome variables. Hope and optimism served as the exogenous predictors within this model.

The fit of both models was evaluated using the following goodness of fit indices: (a) chi-square statistic $\left(\chi^{2}\right)$; (b) root mean square error of approximation (RMSEA; Steiger, 1990); (c) Standardized Root Mean Square Residual (SRMR; Bentler, 1995); (d) Tucker-Lewis Index (TLI; Tucker \& Lewis, 1973); and (e) comparative fit index (CFI; Bentler, 1990). 
A non-significant chi-square statistic shows acceptable model fit. However, chisquare statistics were limited to comparing competing nested models, as they are frequently significant in large samples (Gerbing \& Anderson, 1993). RMSEA values $\leq$ .06 indicate acceptable fit, with smaller values demonstrating better fit (Hu \& Bentler, 1999). SRMR values $\leq .08$ indicate acceptable fit, with smaller values demonstrating better fit (Hu \& Bentler, 1999). TLI and CFI values $\geq .95$ indicate good fit, with larger values demonstrating better fit (Hu \& Bentler, 1999).

\section{Results}

Descriptive statistics (e.g., means, standard deviations, correlations, and Cronbach's alphas) for each of the study measures are presented in Table 1. Hope and optimism were moderately correlated $(r=.55)$, consistent with previous research (Author, Year a; Author, Year b; Snyder, Harris, et al., 1991). Mean levels of hope, optimism, positive affect, negative affect, and life satisfaction were consistent with previous research among college students (Duffy, Allan, \& Bott, 2012; Author, Year a; Watson, Clark, \& Tellegen, 1988). Positive affect was significantly lower at the end of the semester compared to the beginning of the semester, $\mathrm{t}(217)=8.26, \mathrm{p}<.001$. Conversely, life satisfaction $(\mathrm{t}(217)=-3.31, \mathrm{p}=.001)$ and negative affect $(\mathrm{t}(217)=-2.65$, $\mathrm{p}<.009)$ were significantly higher at the end of the semester. Skewness and kurtosis of all variables were examined and found to be within recommended guidelines for assuming normality (Kline, 2011), allowing for standard SEM analyses and fit indices. 
Table 1

Correlations, Means, Standard Deviations, and Cronbach's Alphas for Study Measures

\begin{tabular}{|l|c|c|c|c|c|c|c|c|c|c|c|}
\hline Variable & 1 & 2 & 3 & 4 & 5 & 6 & 7 & 8 & 9 & 10 & 11 \\
\hline 1. GPA & -- & $.29^{*}$ & $.33^{*}$ & .11 & $.14^{*}$ & -.03 & .05 & $.13^{*}$ & -.12 & -.08 & .01 \\
\hline 2. Grade Exp. & & -- & $.34^{*}$ & $.26^{*}$ & $.17^{*}$ & -.08 & .09 & .05 & $-.14^{*}$ & .12 & .06 \\
\hline 3. Final Grade & & & -- & $.14^{*}$ & $.13^{*}$ & -.08 & .01 & $.22^{*}$ & $-.19^{*}$ & .02 & $.19^{*}$ \\
\hline 4. Hope & & & & -- & $.55^{*}$ & $-.26^{*}$ & $.43^{*}$ & $.43^{*}$ & $-.25^{*}$ & $.40^{*}$ & $.50^{*}$ \\
\hline 5. Optimism & & & & & -- & $-.40^{*}$ & $.34^{*}$ & $.45^{*}$ & $-.38^{*}$ & $.35^{*}$ & $.43^{*}$ \\
\hline 6. NA T1 & & & & & & -- & .02 & $-.27^{*}$ & $.46^{*}$ & .01 & $-.20^{*}$ \\
\hline 7. PA T1 & & & & & & & -- & $.23^{*}$ & -.03 & $.53^{*}$ & $.33^{*}$ \\
\hline 8. LS T1 & & & & & & & & -- & $-.16^{*}$ & .12 & $.68^{*}$ \\
\hline 9. NA T2 & & & & & & & & & -- & -.07 & $-.25^{*}$ \\
\hline 10. PA T2 & & & & & & & & & & -- & $.31^{*}$ \\
\hline 11. LS T2 & & & & & & & & & & & -- \\
\hline Mean & 3.24 & 88.75 & 77.60 & 49.81 & 21.24 & 14.90 & 29.34 & 24.86 & 16.00 & 25.45 & 26.02 \\
\hline SD & 0.50 & 4.59 & 10.54 & 6.38 & 4.35 & 5.49 & 7.95 & 5.84 & 6.63 & 8.55 & 5.56 \\
\hline$\alpha$ & & & & .80 & .83 & .83 & .88 & .82 & .89 & .92 & .88 \\
\hline
\end{tabular}

Note: $\mathrm{T} 1 \mathrm{~N}=334 . \mathrm{T} 2 \mathrm{~N}=233 . \mathrm{GPA}=$ grade point average. Grade Exp. $=$ Grade Expectancy. Final Grade $=$ Student's final course grade. $\mathrm{NA}=$ Negative Affect. $\mathrm{PA}=$ Positive Affect. $\mathrm{LS}=$ Life Satisfaction. T1 $=$ Time 1 . T2 $=$ Time $2 *=p<.05$.

Hope and Optimism Predicting Grade Expectancy and Academic Performance

Of the 334 students assessed at Time 1, 306 (91.62\%) students received a course grade at the end of the semester. These 306 students were included in this analysis. Independent samples t-tests were used to compare students with and without course grades on age, GPA, trait hope, trait optimism, and grade expectancy. No significant differences were found. Chi-square tests were used to compare students with and without course grades on gender, race, and year in school, and no significant differences were found.

We conducted a mixed latent-variable/measured-variable path analysis with hope and optimism modeled as latent variables with multiple parceled indicators (Little et al., 
2002), and GPA, grade expectancy, and final course grade as single-indicator measured variables. We modeled hope, optimism, and GPA as exogenous predictors, grade expectancy as the mediator, and final course grade as the outcome. This model showed acceptable fit to the data, $\chi^{2}(28)=58.93, p<0.001$, RMSEA $=.06$ (90\% CI: .04; .08), $\mathrm{SRMR}=.03, \mathrm{TLI}=.95, \mathrm{CFI}=.97,($ Gerbing \& Anderson, 1993; Hu \& Bentler, 1999). Results are shown in Figure 1.

Figure 1.

Path model with GPA, trait hope, and trait optimism predicting grade expectancy and final grade.

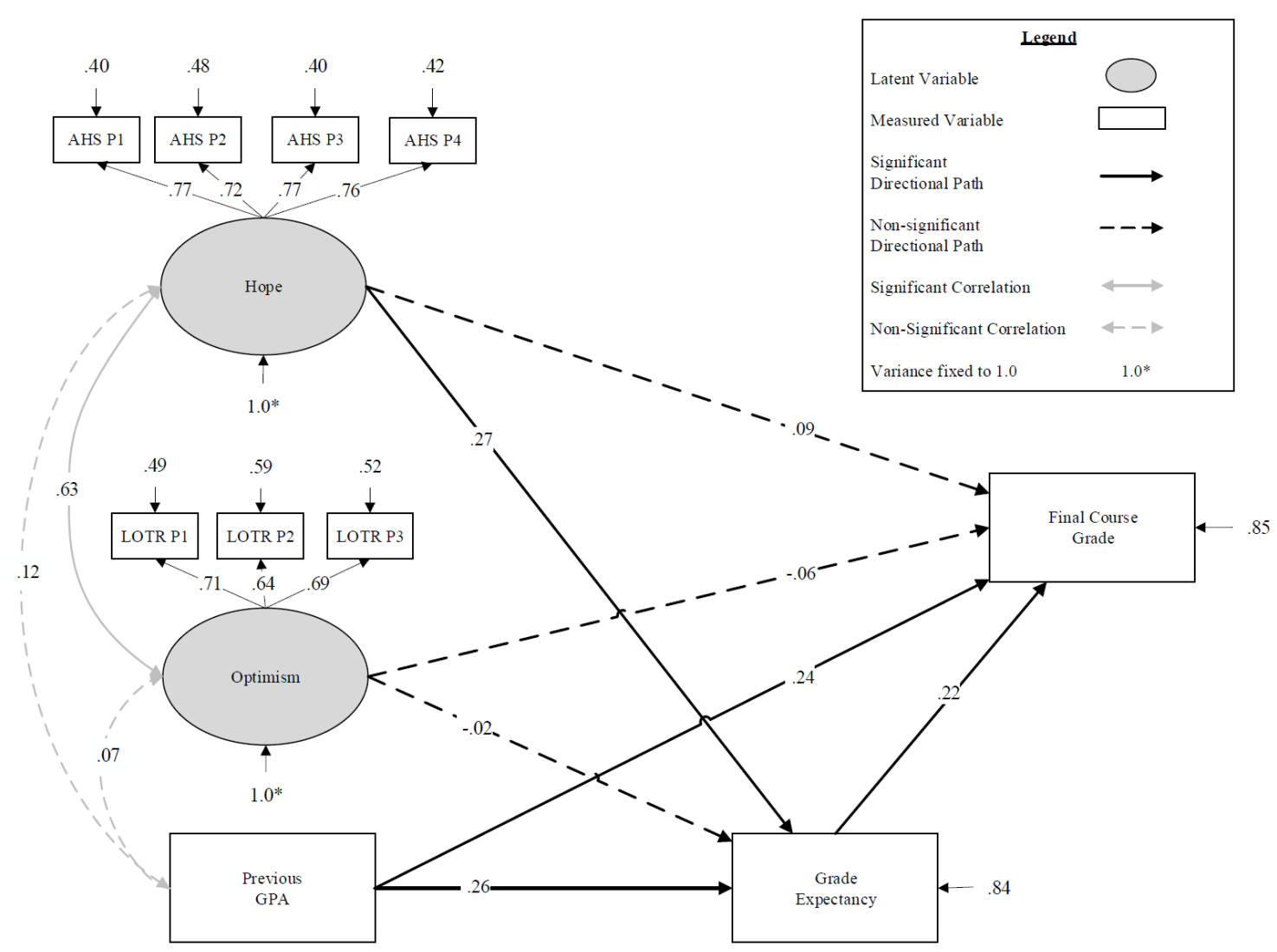

Note: $N=306$. Coefficients represent standardized values. Solid lines represent significant paths at $\mathrm{p}<.05$. Dashed lines represent non-significant paths. 
Hope $(\beta=.27, \mathrm{p}<.001)$ and GPA $(\beta=.26, \mathrm{p}<.001)$ were significant predictors of grade expectancy; whereas, optimism $(\beta=-.02, \mathrm{p}=.861)$ was not. GPA $(\beta=.24, \mathrm{p}<$ $.001)$ and grade expectancy $(\beta=.22, \mathrm{p}<.001)$ were significant predictors of final course grade; whereas, neither hope $(\beta=.09, \mathrm{p}=.284)$ nor optimism $(\beta=-.06, \mathrm{p}=.485)$ were significant predictors. The indirect effect of hope $(a b=.06, \mathrm{p}<.001,95 \% \mathrm{CI}: 0.014$; 0.106) on final course grade (through grade expectancy) was significant, however, suggesting that higher hope may influence academic performance by increasing specific academic expectancies. A summary of the direct and indirect effects of hope, optimism, and GPA on final course grade through specific expectancy is presented in Table 2.

Table 2 Direct and Indirect Effects of Hope, Optimism, and GPA on Final Grade through Specific Expectancy.

\begin{tabular}{|l|c|c|c|r|r|r|}
\hline & $\begin{array}{c}\text { Direct } \\
\text { Effect }\end{array}$ & $\mathrm{p}$ & $\begin{array}{c}95 \% \\
\text { Confidence } \\
\text { Interval }\end{array}$ & $\begin{array}{c}\text { Indirect } \\
\text { Effect }\end{array}$ & $\mathrm{p}$ & $\begin{array}{c}95 \% \\
\text { Confidence } \\
\text { Interval }\end{array}$ \\
\hline Hope & 0.091 & 0.284 & $-0.079,0.261$ & 0.060 & 0.009 & $0.014,0.106$ \\
\hline Optimism & -0.061 & 0.485 & $-0.235,0.113$ & -0.003 & 0.861 & $-0.041,0.035$ \\
\hline GPA & 0.237 & $<0.001$ & $0.133,0.341$ & 0.057 & 0.002 & $0.021,0.093$ \\
\hline
\end{tabular}

We examined whether the above results were moderated by the source of GPA (i.e., high school GPA for freshmen or college GPA for upper-class students). We tested a multi-group model, with freshmen $(\mathrm{n}=180)$ in one group and upper-class students $(\mathrm{n}=$ 154) in the other group. To test if the significant relationships observed in the combined model differed as a function of the source of GPA, we constrained paths to be equal across groups and examined the resulting change in the chi square statistic. A nonsignificant change in chi-square would indicate that there was no significant difference in the strength of the relationship across groups. A series of nested-model comparisons showed no significant differences between the groups in the relationships between: 1) 
GPA and expectancy $\left.\left(\Delta \chi^{2}(1)<0.01, p=.975\right) ; 2\right)$ GPA and final course grade $\left(\Delta \chi^{2}(1)\right.$ $=2.80, \mathrm{p}=.094) ; 3)$ expectancy and final course grade $\left(\Delta \chi^{2}(1)=0.35, \mathrm{p}=.557\right) ;$ or 4$)$ hope and expectancy $\left(\Delta \chi^{2}(1)=0.46, p=.498\right)$. These results suggest that the results of the combined model for Aim 1 apply to both freshmen and upper-class undergraduates. Hope and Optimism Predicting Changes in Subjective Well-being

Of the original 334 students, $233(69.76 \%)$ completed Time 2 measures. Consequently, we used PRELIS (Jöreskog \& Sörbom, 2006) to complete a single imputation of missing data using an expectation maximization algorithm with 200 iterations to generate a single imputed dataset. ${ }^{1}$ The means of Time 1 variables were compared between those with complete and incomplete data using independent samples t-tests. There were significant differences between participants with complete and incomplete data for GPA and life satisfaction. Those with complete data had significantly higher GPAs $(M \mathrm{~s}=3.30 \& 3.11$, respectively $), t(295)=2.88, p=.004$. Those with complete data had significantly higher life satisfaction $(M \mathrm{~s}=25.31 \& 23.75$, respectively), $t(304)=2.12, p=.035$. Gender, race, and year-in-school did not differ between those with complete and incomplete data.

We conducted a measured-variable path analysis ${ }^{2}$ with hope, optimism, and Time 1 subjective well-being (i.e., positive affect, negative affect, and life satisfaction) as exogenous predictors and Time 2 subjective well-being as the outcome variables. We used a simple panel model where each aspect of subjective well-being at Time 2 was

\footnotetext{
${ }^{1}$ We also ran this model using full-information maximum likelihood to handle missing data. We found the same pattern of results, thus, we reported the results of the single imputation method.

${ }^{2}$ Attempting this analysis using a latent-variable approach similar to the one used for the first aim would have reduced the subject-to-parameter ratio to below the 5-to-1 minimum recommended by Kline (2011).
} 
auto-regressed onto its corresponding aspect at Time 1 . Hence, the outcome variables represent changes in subjective well-being over the course of the semester. The model showed acceptable fit to the data, $\chi^{2}(\mathrm{df}=6, N=334)=12.30, \mathrm{p}=0.06, \mathrm{RMSEA}=.06(90 \%$ CI: $0.00 ; 0.10), \mathrm{SRMR}=.03, \mathrm{TLI}=.97, \mathrm{CFI}=.99$. The results are shown in Figure 2.

Figure 2.

Path model predicting changes in negative affect, positive affect, and life satisfaction over the course of the semester.

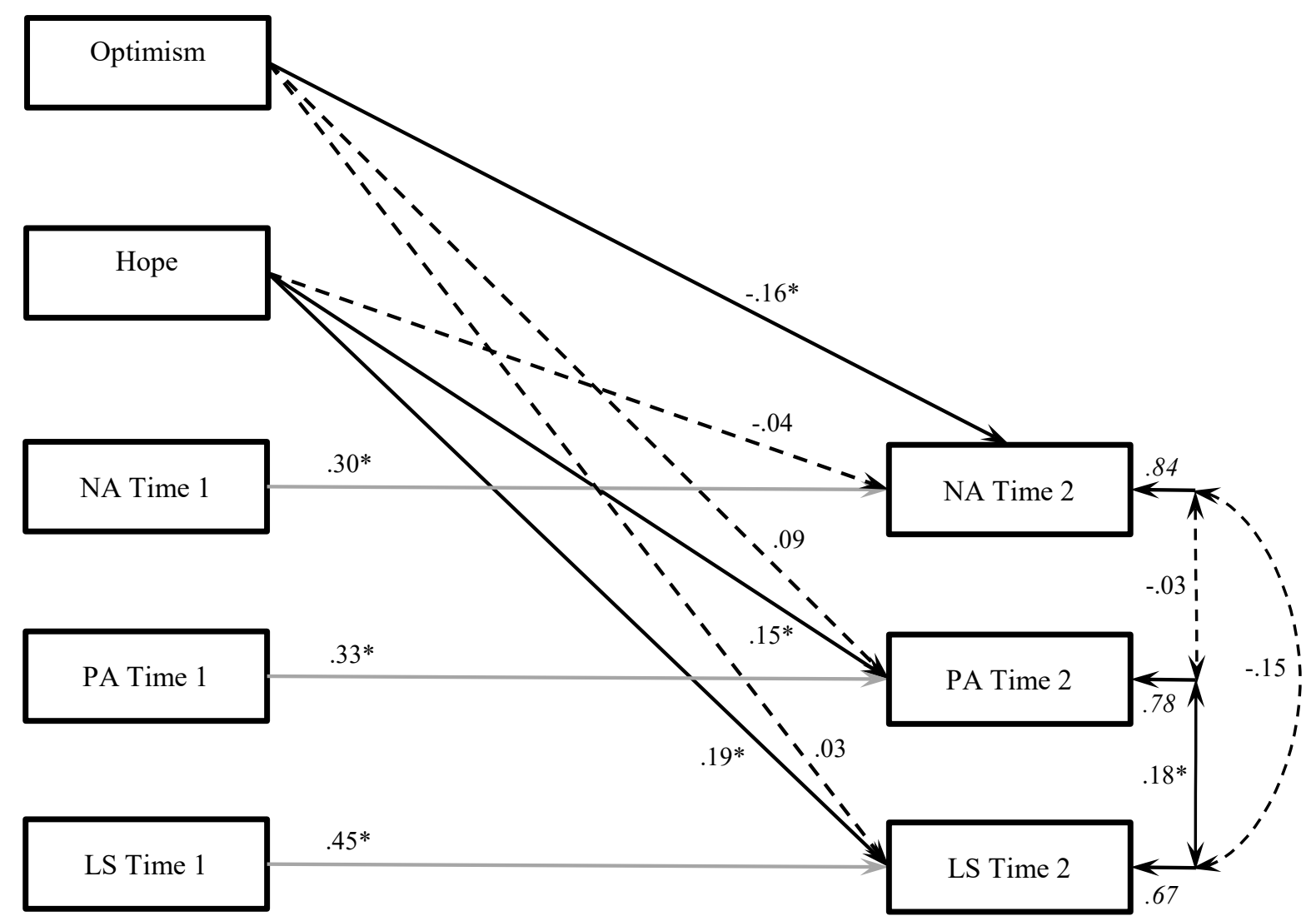

Note: $N=334$. NA $=$ negative affect; $\mathrm{PA}=$ positive affect; $\mathrm{LS}=$ life satisfaction. Single-headed arrow coefficients represent standardized beta weights. Double-headed arrow coefficients represent correlations between residual variances. Italicized coefficients represent residual (unexplained) variance in the criterion variables. Solid lines represent significant paths. Dashed lines represent non-significant paths. Gray lines represent autoregressive paths. All predictor variables were allowed to correlate, but correlations are not shown. $*=p<.05$. 
Time 1 hope predicted changes in positive affect $(\beta=.15, \mathrm{p}<.05)$ and life satisfaction $(\beta=.19, \mathrm{p}<.001)$ but not negative affect $(\beta=-.04, \mathrm{p}=.424)$. In contrast, Time 1 optimism predicted changes in negative affect $(\beta=-.16, \mathrm{p}<.01)$ but not positive affect $(\beta=.09, \mathrm{p}=.073)$ or life satisfaction $(\beta=.03, \mathrm{p}=.121)$. These results suggest that hope and optimism may influence different aspects of subjective well-being, with hope predicting changes in the positive aspects of subjective well-being, and optimism predicting changes in the negative aspect.

\section{Discussion}

We conducted a longitudinal, observational study examining the differential roles of hope (Snyder, 1994) and optimism (Scheier \& Carver, 1985) in predicting academic performance and changes in subjective well-being in a large class of undergraduate students. We found that higher hope, but not optimism, indirectly predicted better academic performance through specific grade expectancy. Both hope and optimism predicted changes in subjective well-being over the course of the semester. However, their patterns of association differed. Higher hope predicted increases in positive affect and life satisfaction, and greater optimism predicted decreases in negative affect.

\section{Hope, Optimism, and Academic Performance}

The current findings suggest that the unique aspects of hope (in the context of optimism) predict academic performance in an undergraduate course, but only indirectly through specific grade expectancies. In contrast, we found that the unique aspects of optimism were unrelated to either specific grade expectancies or academic performance. Our findings are consistent with previous research showing that hope is a unique predictor of academic performance. For example, Author (Year b) found that hope, but 
not optimism, predicted the first-semester grade point averages of law students, even after controlling for undergraduate GPA and LSAT scores. Similarly, Feldman and Kubota (2015) found that hope, but not optimism, was an indirect predictor of undergraduate GPA. Our results add confidence to the existing literature showing that hope and optimism differentially predict academic performance in higher education. These results suggest that it is the unique aspects of hope that are predictive. That is, trait expectancies anchored in beliefs about one's ability to achieve one's goals (i.e., hope) are stronger predictors of academic performance than generalized beliefs about the likelihood of good things happening.

Our finding that hope's association with academic performance was mediated through grade expectancy is consistent with previous research showing that generalized expectancies predict more specific expectancies, which then are the proximal predictors of goal-related outcomes. For example, in a sample of undergraduates, Author (Year a) found that the variance unique to hope predicted grade expectancy at the start of the semester, which then predicted subsequent academic performance in a psychology class. Similarly, Feldman and Kubota (2015) found that trait hope predicted college-student GPA indirectly through two measures of domain-specific expectancies (i.e., academic hope \& academic self-efficacy). Thus, the current findings and previous research suggest that trait hope may indirectly influence goal-directed performance through its influence on specific, performance-related expectancies. Previous research has found that specific academic expectancies influence study behaviors and motivation (Jyoti \& Devi, 2008); study behaviors and motivation then influence student academic performance (Crede \& Kuncle, 2008; Jyoti \& Devi, 2008). Trait hope, through specific expectancies, may exert 
an indirect influence on the behavioral mechanisms that affect student academic performance.

\section{Hope, Optimism, and Subjective Well-Being}

Both hope and optimism predicted changes in subjective well-being over the semester. However, hope and optimism predicted changes in different aspects of subjective well-being. Higher hope predicted increases in positive affect and life satisfaction. Conversely, higher optimism predicted decreases in negative affect. These results support the conceptual distinctions between hope and optimism and suggest that both constructs are important predictors of subjective well-being (Magaletta \& Oliver, 1999, Author, Year b).

Our results suggest that hope is a stronger predictor of positive aspects of subjective well-being (i.e., positive affect and life satisfaction) and optimism is a stronger predictor of negative aspects of subjective well-being (i.e., negative affect). This is consistent with research showing that hope and optimism are differentially related to dimensions of psychological well-being. For example, Gallagher and Lopez (2009) found that hope was not a significant predictor of negative affect; whereas, optimism was. Conversely, hope was a significant predictor of personal growth and autonomy; whereas, optimism was not. Gallagher and Lopez suggested that optimism was a stronger predictor of aspects of hedonic well-being and hope was a stronger predictor of aspects of eudaimonic well-being.

The conceptual distinction between hedonic and eudaimonic well-being may also explain the different trajectories of life satisfaction and affect over the course of the semester. In the present study, students' cognitive well-being (i.e., life satisfaction) 
improved over the course of the semester. In contrast, students' emotional well-being (positive and negative affect) worsened over the course of the semester. The pursuit of important goals (e.g., academic performance) tends to require significant effort (e.g., increased study time), which may lead to detriments in momentary feelings of emotional well-being. However, this sustained effort may lead to increased satisfaction as individuals move closer to valued goals. Our findings are consistent with these conceptual distinctions of subjective well-being. Life satisfaction represents a cognitive appraisal of the worth or value of one's life (Diener, 1984), and this appraisal may be related to the sense of purpose or meaning one finds in one's life (Ryan \& Deci, 2001; Steger, Shin, Shim, \& Fitch-Martin, 2013). If so, then hope, founded on one's pursuit of personally meaningful goals, might be a stronger predictor of life satisfaction than optimism.

In contrast, hedonic aspects of well-being, such as positive and negative affect, may be momentary reactions to stressful events. If so, optimism, anchored in the belief that good things will happen, may be a stronger predictor of emotional reactions to stressful events than hope. This is consistent with Author's (Year a) assertion that hope is built on beliefs about the self's ability to achieve controllable goals; whereas, optimism is built on beliefs about the world and the relative likelihood of good versus bad events.

\section{Practical Implications for Education}

The present findings suggest that expectancies may have beneficial influences on undergraduate student learning and subjective well-being. Specifically, efforts to increase hope may yield better academic achievement, independent of students' innate abilities or previous academic experience. For example, instructors could ask students to write down 
a personal learning goal for the course, followed by several concrete steps to reach this goal. Students could list likely barriers and generate alternative strategies to overcome these barriers. In addition, students could list techniques (e.g., positive self-talk statements) to maintain their motivation to pursue their learning goals. Finally, instructors could have students visualize themselves going through these steps, including overcoming obstacles. This "goal mapping" and visualization exercise has been shown to increase undergraduate hope levels and was associated with making greater progress toward valued goals (Feldman \& Dreher, 2012). Similarly, a hope-focused intervention for first-year college students resulted in higher grades among participants whose hope increased in response to the intervention (Feldman, Davidson, \& Margalit, 2015). Hopefocused interventions may also improve student well-being by increasing their experience of positive affect and sense of life satisfaction.

Interventions that increase optimistic thinking may improve student resiliency by changing how stressors are appraised, thereby reducing negative emotions related to the stress response. For example, at the beginning of the semester, students could imagine stressful situations likely to arise and then list ways to maintain a positive outlook in the midst of these stressors. Sergeant and Mongrain (2014) found that such an optimism intervention, delivered online, decreased dysfunctional attitudes, resulting in fewer depressive symptoms. Similarly, Littman-Ovadia and Nir (2014) found that an optimism intervention decreased negative affect and emotional exhaustion, but did not affect positive affect or life satisfaction. 


\section{Limitations \& Future Directions}

There are limitations worth noting. First, the present sample consisted of mostly young, white, female students. This sample is representative of typical undergraduate populations at universities in the United States, and these findings most likely apply to college students pursuing educational goals. However, these results may not generalize to more diverse student populations or those pursuing goals outside of an academic context. However, research has shown that average hope levels do not vary between racial and ethnic groups (Edwards \& McClintock, 2018), and hope has been shown to be an important predictor of academic performance in racially and socioeconomically diverse populations (Dixson, Keltner, Worrell, \& Mello, 2018). Moreover, hope predicts goaldirected performance in other life domains (see Feldman, Rand, Kahle-Wrobleski, 2009), including athletic performance (Curry, Snyder, Cook, Ruby, \& Rehm, 1997). In addition, hope and optimism are associated with better physical and psychological well-being in other populations, including American Indian and Native Alaskan college students (O’Keefe \& Wingate, 2013) and older community-dwelling adults (Barnett, 2014). Nevertheless, research examining the differential roles of hope and optimism in more diverse populations and life contexts is needed.

Second, this study focused on Snyder's (1994) conceptualization of hope, which has been criticized as being overly focused on personal cognitions and agency while excluding aspects and sources that others consider essential to the concept of hope (Aspinwall \& Leaf, 2002). For example, Miceli and Castelfranchi (2010) noted that Snyder's model emphasized hope's role in increasing one's motivation to strive for goals (i.e., active hope). However, hope may promote more passive reactions. For example, 
hoping that a desired outcome will happen due solely to external features may encourage people to passively wait for the outcome to happen. Indeed, research has shown that fantasizing about a desired goal reduces motivation (Oettingen \& Mayer, 2002). There are other conceptualizations of hope in the literature (e.g., Herth, 1991), and the associations between hope and life outcomes may vary depending on the model of hope used. Research is needed to clarify the importance of different aspects of hope, including its varied sources (e.g., internal versus external) and its different manifestations (e.g., active versus passive; see also Gasper, Spencer, \& Middlewood, 2019).

Third, this study focused on trait expectations. However, Snyder's (1994) model posits that hopeful thinking occurs along a continuum, including global trait hope, domain-specific hope, and hope for specific goals (Feldman, Rand, \& Kahle-Wrobleski, 2009). More specific instantiations of hope and optimism may be stronger predictors of academic performance and subjective well-being. For example, Feldman and Kubota (2015) found that academic domain-specific hope directly predicted academic performance among undergraduates; whereas, trait hope did not. However, trait hope indirectly predicted academic performance through academic domain-specific hope. These results are congruent with our results in that trait hope appears to have an indirect influence on academic performance through more specific expectancy beliefs. More research is needed clarifying the complex relationships among trait-level expectations, specific expectations, and important life outcomes, such as academic performance and subjective well-being.

Fourth, given this was an observational study we cannot make causal claims about the roles of hope and optimism with regard to academic performance and subjective well- 
being. Research is needed studying the effects of interventions targeting hope and optimism. Several intervention studies are promising in that they demonstrate the hope and optimism can be increased (Malouff \& Schutte, 2017; Rosenstreich, Feldman, Davidson, Maza, \& Margalit, 2015) and that there are subsequent improvements in goaldirected performance and psychological well-being as a result (Feldman, Davidson, \& Margalit, 2015; Sergeant \& Mongrain, 2014).

Fifth, the goal of this study was to examine the unique associations of hope and optimism with outcomes to better understand their differences. Our analyses statistically held hope constant while examining the unique associations of optimism and vice versa. Thus, our conclusions are based on artifically partialed relationships. In reality, hope and optimism likely influence each other and work in conjunction to affect a host of important life outcomes. Increasing hope likely increases optimism, and the positive contributions of one are likely related to the positive contributions of the other. However, research examining the differences between hope and optimism is necessary in order to determine which one is likely to be the most efficient target of intervention for particular outcomes.

Finally, there were significant differences between individuals who did and did not complete this study in its entirety. Individuals who completed the study had significantly higher grade point averages and life satisfaction than non-completers. This differential drop out may have influenced the results concerning hope, optimism, and subjective well-being. However, findings were in line with previous research, thus we have increased confidence in the realibility of these results.

\section{Conclusion}


Hope and optimism are linked with better academic performance and psychological well-being. This study replicates and extends existing research on these two constructs. Hope may be the stronger predictor of academic performance. However, both constructs appear to predict changes in subjective well-being over time. Further research, including intervention studies on hope and optimism, may increase our ability to create a more positive educational experience for university students. 


\section{References}

Aspinwall, L. G., \& Leaf, S. L. (2002). In search of the unique aspects of hope: Pinning our hopes on positive emotions, future-oriented thinking, hard times, and other people. Psychological Inquiry, 13, 276-288.

Bailey, T. C., Eng, W., Frisch, M. B., \& Snyder, C. R. (2007). Hope and optimism as related to life satisfaction. The Journal of Positive Psychology, 2, 168-175.

Bandura, A. (1977). Self-efficacy: toward a unifying theory of behavioral change. Psychological Review, 84, 191-215.

Barnett, M. D. (2014). Future orientation and health among older adults: The importance of hope. Educational Gerontology, 40, 745-755.

Bentler, P. M. (1990). Comparative fit indexes in structural models. Psychological Bulletin, 107, 238-246.

Bentler, P.M. (1995). EQS structural equations program manual. Encino, CA: Multivariate Software.

Brunstein, J. C. (1993). Personal goals and subjective well-being: A longitudinal study. Journal of Personality and Social Psychology, 65, 1061-1070.

Bryant, F. B., \& Cvengros, J. A. (2004). Distinguishing hope and optimism: Two sides of a coin, or two separate coins? Journal of Social and Clinical Psychology, 23, 273302.

Carver, C. S., Pozo, C., Harris, S. D., Noriega, V., Scheier, M. F., Robinson, D. S., ... \& Clark, K. C. (1993). How coping mediates the effect of optimism on distress: a 
study of women with early stage breast cancer. Journal of Personality and Social Psychology, 65, 375-390.

Chemers, M. M., Hu, L. T., \& Garcia, B. F. (2001). Academic self-efficacy and first year college student performance and adjustment. Journal of Educational psychology, 93, 55-64.

Cozzarelli, C. (1993). Personality and self-efficacy as predictors of coping with abortion. Journal of Personality and Social Psychology, 65, 1224-1236.

Crede, M., \& Kuncle, N.R., (2008). Study habits, skills, and attitudes: The third pillar supporting collegiate academic performance. Perspectives on Psychological Science, 3(6), 425-453.

Cummins, R. A., Lau, A. A., Mellor, D., \& Stokes, M. A. (2009). Encouraging governments to enhance the happiness of their nation: Step 1: Understand subjective wellbeing. Social Indicators Research, 91, 23-36.

Curry, L. A., Snyder, C. R., Cook, D. L., Ruby, B. C., \& Rehm, M. (1997). Role of hope in academic and sport achievement. Journal of Personality and Social Psychology, 73, 1257-1267.

Diener, E. (1984). Subjective well-being. Psychological Bulletin, 95, 542-575.

Diener, E. D., Emmons, R. A., Larsen, R. J., \& Griffin, S. (1985). The satisfaction with life scale. Journal of Personality Assessment, 49, 71-75. 
Dixon, D. D., Keltner, D., Worrell, F. C., \& Mello, Z. (2018). The magic of hope: Hope mediates the relationship between socioeconomic status and academic achievement. The Journal of Educational Research, 111, 507-515.

Duffy, R. D., Allan, B. A., \& Bott, E. M. (2012). Calling and life satisfaction among undergraduate students: Investigating mediators and moderators. Journal of Happiness Studies, 13, 469-479.

Edwards, L. M., \& McClintock, J. B. (2018). A cultural context lens of hope. In M. W. Gallagher \& S. J. Lopez (Eds.) The Oxford Handbook of Hope (95-104). New York: Oxford University Press.

Feldman, D. B., Davidson, O. B., \& Margalit, M. (2015). Personal resources, hope, and achievement among college students: The conservation of resources perspective. Journal of Happiness Studies, 16, 543-560.

Feldman, D. B., \& Dreher, D. E. (2012). Can hope be changed in 90 minutes? Testing the efficacy of a single-session goal-pursuit intervention for college students. Journal of Happiness Studies, 13, 745-759.

Feldman, D. B., \& Kubota, M. (2015). Hope, self-efficacy, optimism, and academic achievement: Distinguishing constructs and levels of specificity in predicting college grade-point average. Learning and Individual Differences, 37, 210-216.

Feldman, D. B., Rand, K. L., \& Kahle-Wrobleski, K. (2009). Hope and goal attainment: Testing a basic prediction of hope theory. Journal of Social and Clinical Psychology, 28, 479-497. 
Friedman, B. A., \& Mandel, R. G. (2009). The prediction of college student academic performance and retention: Application of expectancy and goal setting theories. Journal of College Student Retention: Research, Theory \& Practice, 11, 227-246.

Frisch, M. B., Clark, M. P., Rouse, S. V., Rudd, M. D., Paweleck, J. K., Greenstone, A., \& Kopplin, D. A. (2005). Predictive and treatment validity of life satisfaction and the quality of life inventory. Assessment, 12, 66-78.

Gallagher, M. W., \& Lopez, S. J. (2009). Positive expectancies and mental health: Identifying the unique contributions of hope and optimism. The Journal of Positive Psychology, 4, 548-556.

Gasper, K., Spencer, L., \& Middlewood, B. (2019). Differentiating hope from optimism by examining self-reported appraisals and linguistic content. The Journal of Positive Psychology, 15, 220-237.

Gerbing, D. W., \& Anderson, J. C. (1993). Monte Carlo evaluations of goodness-of-fit indices for structural equation models. Sage Focus Editions, 154, 40-40.

Herth, K. (1991). Development and refinement of an instrument to measure hope. Scholarly Inquiry for Nursing Practice: An International Journal, 5(1), 39-51.

Hu, L. T., \& Bentler, P. M. (1999). Cutoff criteria for fit indexes in covariance structure analysis: Conventional criteria versus new alternatives. Structural Equation Modeling: A Multidisciplinary Journal, 6, 1-55. 
Irving, L. M., Crenshaw, W., Snyder, C. R., Francis, P., \& Gentry, G. (1990, May). Hope and its correlates in a psychiatric inpatient setting. In 62nd annual meeting of the Midwestern Psychological Association.

Jöreskog, K. G., \& Sörbom, D. (2006). LISREL 8.80 for Windows [Computer software].

Jyoti, P., \& Devi, P.N. (2008). Achievement motivation and its impact on academic stress, study habits, and academic performance among high school students. Social Science International, 24(2), 107-115

Keefe, J. R., Amsterdam, J., Li, Q. S., Soeller, I., DeRubeis, R., \& Mao, J. J. (2017). Specific expectancies are associated with symptomatic outcomes and side effect burden in a trial of chamomile extract for generalized anxiety disorder. Journal of Psychiatric Research, 84, 90-97.

Kline, R. (2011). Principles and Practice of Structural Equation Modeling, 3rd edition Guilford Press. New York.

Kool, A., Mainhard, M. T., Jaarsma A. D. C., Brekelmans M. \& van Beukelen, P. (2016) Academic success and early career outcomes: Can honors alumni be distinguished from non-honors alumni? High Ability Studies, 27, 179-192.

Kuncel, N. R., Ones, D. S., \& Sackett, P. R. (2010). Individual differences as predictors of work, educational, and broad life outcomes. Personality and Individual Differences, 49, 331-336.

Kwon, P. (2002). Hope, defense mechanisms, and adjustment: Implications for false hope and defensive hopelessness. Journal of Personality, 70, 207-231. 
Lilienfeld, S. O. (2017). Psychology's replication crisis and the grant culture: Righting the ship. Perspectives on Psychological Science, 12, 660-664.

Little, T. D., Cunningham, W. A., Shahar, G., \& Widaman, K. F. (2002). To parcel or not to parcel: Exploring the question, weighing the merits. Structural Equation Modeling, 9, 151-173.

Littman-Ovadia, H., \& Nir, D. (2014). Looking forward to tomorrow: The buffering effect of a daily optimism intervention. The Journal of Positive Psychology, 9, 122-136.

Lyubomirsky, S., King, L., \& Diener, E. (2005). The benefits of frequent positive affect: Does happiness lead to success? Psychological Bulletin, 131, 803.

Magaletta, P. R., \& Oliver, J. M. (1999). The hope construct, will, and ways: Their relations with self-efficacy, optimism, and general well-being. Journal of Clinical Psychology, 55, 539-551.

Malouff, J. M., \& Schutte, N. S. (2017). Can psychological interventions increase optimism? A meta-analysis. The Journal of Positive Psychology, 12, 594-604.

Miceli, M., \& Castelfranchi, C. (2010). Hope: The power of wish and possibility. Theory \& Psychology, 20, 251-276.

Muthén, L. K., \& Muthén, B. O. (2018). Mplus 8.2 for Windows [Computer Software].

O'Keefe, V. M., \& Wingate, L. R. (2013). The role of hope and optimism in suicide risk for American Indians/Alaska Natives. Suicide and Life-Threatening Behavior, 43, 621-633. 
Oettingen, G., \& Mayer, D. (2002). The motivating function of thinking about the future: Expectations versus fantasies. Journal of Personality and Social Psychology, 83, 1198-1212.

Author. (Year a).

Author, (Year b).

Rosenstreich, E., Feldman, D. B., Davidson, O. B., Maza, E., \& Margalit, M. (2015). Hope, optimism and loneliness among first-year college students with learning disabilities: A brief longitudinal study. European Journal of Special Needs Education, 30, 338-350.

Ryan, R. M., \& Deci, E. L. (2001). On happiness and human potentials: A review of research on hedonic and eudaimonic well-being. Annual Review of Psychology, 52, 141-166.

Samuel, R., Bergman, M. M., \& Hupka-Brunner, S. (2013). The interplay between educational achievement, occupational success, and well-being. Social Indicators Research, 111, 75-96.

Scheier, M. F., \& Carver, C. S. (1985). Optimism, coping, and health: Assessment and implications of generalized outcome expectancies. Health Psychology, 4, 219247.

Scheier, M. F., Matthews, K. A., Owens, J. F., Magovern, G. J., Lefebvre, R. C., Abbott, R. A., \& Carver, C. S. (1989). Dispositional optimism and recovery from coronary artery bypass surgery: the beneficial effects on physical and 
psychological well-being. Journal of Personality and Social Psychology, 57, 1024-1040.

Scheier, M. F., Carver, C. S., \& Bridges, M. W. (1994). Distinguishing optimism from neuroticism (and trait anxiety, self-mastery, and self-esteem): A reevaluation of the Life Orientation Test. Journal of Personality and Social Psychology, 67, 1063-1078.

Seligman, M. E., Ernst, R. M., Gillham, J., Reivich, K., \& Linkins, M. (2009). Positive education: Positive psychology and classroom interventions. Seligman, M. E., Ernst, R. M., Gillham, J., Reivich, K., \& Linkins, M. (2009). Positive education: Positive psychology and classroom interventions. Oxford Review of Education, 35, 293-311.

Sergeant, S., \& Mongrain, M. (2014). An online optimism intervention reduces depression in pessimistic individuals. Journal of Consulting and Clinical Psychology, 82, 263-274.

Snyder, C. R., Harris, C., Anderson, J. R., Holleran, S. A., Irving, L. M., Sigmon, S. T., \& ... Harney, P. (1991). The will and the ways: Development and validation of an individual-differences measure of hope. Journal of Personality and Social Psychology, 60, 570-585.

Snyder, C. R. (1994). The psychology of hope: You can get there from here. Simon and Schuster.

Snyder, C. R. (2002). Hope theory: Rainbows in the mind. Psychological Inquiry, 13, 249-275. 
Snyder, C. R., Shorey, H. S., Cheavens, J., Pulvers, K. M., Adams III, V. H., \& Wiklund, C. (2002). Hope and academic success in college. Journal of Educational Psychology, 94, 820-826.

Steger, M. F., Shin, J. Y., Shim, Y., \& Fitch-Martin, A. (2013). Is meaning in life a flagship indicator of well-being? In A. S. Waterman (Ed.), The best within us: Positive psychology perspectives on eudaimonia (pp. 159-182). Washington, DC, US: American Psychological Association.

Steiger, J. H. (1990). Structural model evaluation and modification: An interval estimation approach. Multivariate Behavioral Research, 25, 173-180.

Tucker, L. R., \& Lewis, C. (1973). A reliability coefficient for maximum likelihood factor analysis. Psychometrika, 38, 1-10.

Watson, D., Clark, L. A., \& Tellegen, A. (1988). Development and validation of brief measures of positive and negative affect: The PANAS scales. Journal of Personality and Social Psychology, 54, 1063-1070. 